\title{
Health Literacy Among Migrants in the EU: A Collection of Best Available Interventions and Indirect Measures
}

\author{
Tessa Naus \\ Faculty of Health, Medicine and Life Sciences, Maastricht University, Maastricht, Netherlands \\ Email address: \\ t.naus@student.maastrichtuniversity.nl \\ To cite this article: \\ Tessa Naus. Health Literacy Among Migrants in the EU: A Collection of Best Available Interventions and Indirect Measures. Science \\ Journal of Public Health. Vol. 6, No. 1, 2017, pp. 1-5. doi: 10.11648/j.sjph.20180601.11
}

Received: August 25, 2017; Accepted: September 20, 2017; Published: November 21, 2017

\begin{abstract}
Migrants have lower health literacy (HL) levels compared with native-born. To reduce health inequalities, this research intends to achieve recommendations for a HL strategy for migrants. Additionally, it identifies indirect measures for HL. A literature review acquired existing interventions improving migrants' HL, variables to measure HL indirectly and studies measuring these variables. Cancer screening and maternal mortality indirectly measure migrants' HL deficiencies. Workshops, language courses, multicultural webpages, health educators, and migrant-friendly hospitals improve migrants' HL. EU countries should develop comprehensive HL strategies to reduce health inequalities between migrants and native-born. However, there is a lack of evidence-based interventions.
\end{abstract}

Keywords: Health Literacy, Migrants, European Union, Interventions, Indirect Measures

\section{Introduction}

The European Union has a long history of migration. In the first half of the twentieth century European citizens mainly emigrated to other countries in the world. However, between 1945 and 2009 this development was reversed with the influx of populations coming in from other parts of the world because of resettlements after World War 2, decolonization, strong economic growth in Western Europe, political crises, and Eastern enlargement of the European Union (EU) [1]. Overall, a total of 33.5 million non-EU born migrants were living in the EU on 1 January 2014, while 17.9 million migrants were residing in a different EU Member State than they were born [2]. These numbers rapidly increased with over a million migrants, primarily refugees, crossing into Europe in 2015 [3]. The high influx caused a "crisis" among the European countries, additionally it created a division in the European Union how best to deal with these migrating people [3]. Nevertheless, it are mainly the non-EU born migrants who are putting pressure on the system, as migrants from the EU countries do not have to apply for asylum or a visa: Article 45 of the Treaty on the Functioning of the European Union allows free movement of EU citizens between the countries so people can travel easily across the borders to live and work freely.
In today's world, every migrant is expected to meet the complex demands of society concerning health care [4]. They should know how to inform themselves about health and disease, how to describe their complaints to health care providers, how to ask those providers the right questions, are expected to follow-up their appointments, and they should be able to apply health information to their own situation [4]. All these skills are summarized into one concept: "health literacy". Research demonstrates that migrants generally score lower on health literacy measures [5]. This can be explained by the fact that educational resources and information programs only partly reach migrants, mostly due to economic and social barriers [5]. This has implications for migrants as limited health literacy often correlates with a lack of access to health services, ability to effectively self-manage health, understanding available and relevant information, and to make health-related decisions [5]. As native-born have a higher level of health literacy, their differences in health behavior cause health inequalities between them and the migrants [5]. An adequate level of health literacy could avoid these health inequalities [5]. Hence, the aim of this research is to achieve recommendations for a strategy to improve health literacy among migrants, particularly as a large number are entering the EU at the moment. These recommendations can then be applied by countries in the EU. 
To achieve this outcome, the best available interventions which are already conducted to improve migrants' health literacy, and the outcomes they had will be identified.

However, before the countries are recommended to invest in such a strategy, the author intends to conduct more research into demonstrating actual health literacy deficiencies of migrants. As studies about direct measurements of health literacy among migrants are sparse, the author looks into indirect measurements available to measure health literacy among migrants.

\section{Methods}

\subsection{Literature Search Best Available Interventions}

The electronic database PubMed was used to identify the best available interventions. Combinations of the following keywords were used: "((health literacy) AND intervention)" and "((health education) AND intervention)" with: migrants, immigrants, refugees, family reunification, education migrants, students, development displaces, illegal migrants, economic migrants and labor migrants, to cover all articles concerning health literacy interventions and migrants. Additionally, snowball sampling was conducted through the reference collections of the identified articles. Finally, "grey literature" was collected, since there are many successful projects available which can be used as recommendation for a strategy to improve health literacy among migrants.

\subsection{Study Selection Best Available Interventions}

Initially, 4536 articles were retrieved from the database, after removing 333 duplicate articles. One article was identified through snowball sampling. The author reviewed the titles and abstracts to assess whether they were relevant to health literacy interventions and migrants. From the 4537 articles, eighteen made it to full-text review. Subsequent, the studies were looked over for the following inclusion criteria: (1) migrants as focus group, (2) one or several interventions aiming to improve health literacy, (3) a description of the performed intervention(s), and (4) an overview of the outcome(s) of the study. Thirteen articles were excluded as they focused on health promotion rather than on health literacy aspects. Eventually, five studies met the inclusion criteria. Although the main focus of this research is on migrants residing in the European Union, studies writing about migrants living outside the EU were included as well, since European literature is thin on this topic.

Additionally, the author came across the study "HEALIT4EU" [6] through suggestion of the supervisor. This study produced insight into all intervention studies on health literacy that have been conducted in the EU Member States, as well as the policies, actions, and programs that they initiated and implemented [6]. Hence, it covers all health literacy interventions and projects $(\mathrm{N}=5)$ focusing on migrants residing in the EU. Literature suggestion by the supervisor resulted in two additional interventions.

\subsection{Literature Search Indirect Measures HL}

PubMed was used to identify studies using indirect measurements to make statements about migrant's health literacy levels. The keywords "(indirect measure) AND health literacy" and "(indirect measure) AND health education" were combined. Snowball sampling was initiated as well, although it resulted in no extra studies.

\subsection{Study Selection Indirect Measures HL}

Six and 129 hits were retrieved from the database respectively. Subsequent, all English or Dutch titles and abstract were reviewed by the author to identify whether the article discussed an indirect measure for health literacy. Three articles made it to full-text review. Eventually, one article was included: the other two were excluded as they did not prove some kind of association between the variable and health literacy. Nevertheless, they initiated a new search term: "(maternal mortality) AND health literacy". The fulltext of six out of 187 articles was reviewed. One article was included: the other articles only measured maternal health literacy or rather focused on child mortality. For one article the full-text was not available.

\subsection{Literature Search Outcomes Indirect Measures HL}

Finally, studies measuring the outcomes of the earlier identified variables $[14,15]$ among migrants, to make indirect statements about their health literacy levels, were searched for. The keywords "(cervical cancer screening) AND migrants" and "(maternal mortality) AND migrants" were combined to retrieve all English and Dutch studies concerning these terms in PubMed. Additionally, snowball sampling was conducted through the references of the identified articles.

\subsection{Study Selection Outcomes Indirect Measures HL}

The combination of these $\mathrm{Me} \mathrm{SH}$ terms resulted in 32 and 87 hits respectively. The articles needed to consist of the same criteria as mentioned in section 2.2. Before articles were passed on for full-text review, the author recognized that too few studies discussed cervical cancer participation by migrants and no conclusions could be based upon this. Therefore, this research tried a literature search on a similar screening used by women: breast cancer screening. The keywords "(breast cancer screening) AND migrants" resulted in 43 hits. Collecting literature through snowball sampling resulted in three additional hits. Eventually, the full-text of fifteen articles were reviewed. In the end, five studies could be included for the first search term. For the second term a systematic literature review about maternal mortality among migrants in Western Europe was identified.

\section{Results}

\subsection{Characteristics Interventions Retrieved Through Pub Med}

All but two studies $[10,11]$ were conducted in the USA. 
Moreover, all used an experimental study design. The study participants were recruited from the following settings: community partnerships [10], through local radio and television stations [9], community nurse [7], via English-asa-second-language classrooms [8], and social and welfare clubs [11]. All but two studies [8,9], which both added health information to language courses, used different types of interventions such as: 1) workshops wherein health information was presented to the participants, with the use of activities such as lectures, role-play exercises, demonstrations, drama, group presentations and group discussions [10], 2) a community conference wherein awareness was raised, mainly among the local health care providers, about the Somali Bantu refugees' presence in the American community, their culture and their information needs, with additional education for Somali Bantu refugee mothers about necessary health information through welcome packages [7], and 3) an online depression information intervention, consisting of multilingual information about depression [11].

\subsection{Outcomes Interventions Retrieved Through Pub Med}

Only one study [9] specifically conducted measurements to gain outcomes about health literacy, and used the Test of Functional Health Literacy in Adults (TOFHLA) for this. Another study [11] aimed to measure depression literacy directly, which is a specific type of (mental) health literacy, through the Analyses of Variances (ANOVA). Two other studies measured improved health literacy outcomes indirectly, through participatory observation, in-depth individual interviews [10] and surveys [8]. One study did not measure health literacy at all [7]. All studies except one [7] achieved improved levels of health literacy with their interventions among migrants. Two studies $[9,11]$ could even demonstrate a significantly higher increase in the intervention group compared with the control group.

\subsection{Characteristics Interventions Retrieved Through "Grey Literature"}

The seven interventions, project and initiatives retrieved via "grey literature" were all conducted in the EU. They are quite diverse from each other, as well as from the interventions retrieved via PubMed. Nevertheless, a trend can be identified among four interventions: the use of health educators. One project [12], "MiMi, Mit Migranten für Migranten" (with migrants for migrants), used a migrant from the own community, who informs members of his or her migrant community about the German health care system. Another project [13], "Gesundheit kommt nachhause - Mehr Wissen hilft" (Health is coming home - more knowledge helps!), sends competent women from the migrant's own culture to the migrants' home. In the houses of the participants, a course about health related issues is given to small groups. Project ARTEMIS [6] uses a general health educator, who is a specialized person able to detect the social and health care needs of migrants, and teaches and directs them to the health services they need most. The remainder type [14] of health educator is the bicultural worker, who provides a bridge to reduce the social distance that often exists between health professionals and migrants. Such workers can be particularly effective at increasing the understanding of health communications, improving access to health services by navigating migrants to health services and appointments, negotiating migrants' expectations, and inspiring greater patient engagement. For health professionals, such workers can be a support to understand different health beliefs and social circumstances that may affect decision making [14].

Of the remaining projects, one [15] implements interpreting services, training for both patients and staff training towards cultural competence, and more migrantfriendly information with the help of improved signposts using pictograms to achieve improve health literacy rates, while the project "HEALTH_LITERACY_4_EVERYONE" [6] uses activities such as workshops in English language, excursions to different health service centers, and an empowerment-communication course for health. The final article [4] provides recommendations about how health professionals can improve their health literacy behavior such as by using signal-cards.

\subsection{Outcomes Interventions Retrieved Through “Grey Literature"}

All but two studies [4, 6: project ARTEMIS] demonstrate that they were successful, particularly in terms of achieving improved health literacy levels among migrants. However, due to a lack of scientific data, further evaluation is needed to assess how these interventions should be implemented in another time and setting in order to be effective.

\subsection{Indirect Measures Health Literacy}

Two variables indirectly demonstrating a link between being a migrant and having a lower level of health literacy were identified through PubMed: cervical cancer screening and maternal mortality. For the variable cervical cancer screening a systematic literature review [16] was found, with nine out of twelve studies indicating a positive association between health literacy and cervical cancer screening across different ethnic groups. For maternal mortality a negative relation was demonstrated with female literacy through a regression analysis [17]. Female literacy consists of several social determinants such as level of education and reading level: these determinants are important predictors for health literacy as well.

\subsection{Outcomes Indirect Measures Health Literacy}

With the amount of studies for cervical cancer screening being too limited, the author decided to change to a cancer type which is often screened for in women as well: breast cancer. In total, five articles were identified, and four [18, 19, 20, 21] of them demonstrate that migrants in the EU participate less in breast cancer screening compared with native-born. The fifth 
study [22] presents the opposite, although it makes use of a name-based algorithm which poses a risk of these women being second-generation migrants, and hence native-born. Although one of the other studies [20] indicates that the participation rates of all ethnic groups have increased the past decade, the numbers still remain behind those of the native-born. Taking the evidence of the link between health literacy and (cervical) cancer screening into consideration, a person could hence say that migrants have lower health literacy.

For the variable maternal mortality a systematic literature review was identified [23], which demonstrates a two times higher relative risk among migrant women for maternal mortality compared with native-born women $(95 \% \mathrm{CI}$ : 1.72 2.33). Although a person can see the maternal mortality rates of migrant women decreasing over the years, and those from native-born slightly increasing, the evidence still indicates lower health literacy levels among migrants.

\section{Conclusions}

Migrants screen less for breast cancer and have higher maternal mortality rates compared with native-born, which (indirectly) indicates lower health literacy rates among migrants. These outcomes confirm the earlier made assumptions about migrants' health literacy levels. Although both variables improved the last decade, there is still a huge gap between migrants and native-born. To reduce these health inequalities, EU countries should develop comprehensive health literacy strategies. However, the lack of effective evidence based interventions in general makes it impossible to do this right now. Hence, more research should be conducted towards new interventions. However, the EU countries cannot wait for more research evidence to show up with the refugee crisis at this moment in time. Therefore, the recommendation of this research is to at least implement interventions demonstrating they might help, and definitely do no harm. Examples of such interventions are adding health information to language courses, developing multicultural websites with health content for migrants, and the use of community health educators.

\section{Acknowledgements}

I wish to express my sincere gratitude to my supervisor, Prof. Dr. Helmut Brand, for providing me an opportunity to do my internship at the Department of International Health, CAPHRI, Maastricht University and for his guidance, suggestions and improvements throughout the project.

\section{References}

[1] Wanner, P. Migration Trends in Europe. European Population Series 7. Strasbourg: Council of Europe, 2002.

[2] Eurostat. Migration and migrant population statistics, 2015.

[3] BBC. Migrant crisis: Migration to Europe explained in seven charts, 2016.
[4] Nusselder, A. Health literacy en laaggeletterdheid [Health literacy and low literacy]. Tijdschrift voor praktijkondersteuning, 3, (2012), 66-70.

[5] WHO. Health literacy - the solid facts. Copenhagen: WHO Regional Office for Europe, 2013.

[6] European Commission. Study on sound evidence for a better understanding of health literacy in the European Union. Luxembourg: Publications Office of the European Union, 2014.

[7] Eisenhauer, E. R., Mosher, E. C., Lamson, K. S., Wolf, H. A., Schwartz, D. G. Health education for Somali Bantu refugees via home visits. Health Information \& Libraries Journal, 29, 2 (2012), 152-61.

[8] Santos, M. G., Handley, M. A., Omark, K., Schillinger, D. ESL participation as a mechanism for advancing health literacy in immigrant communities. Journal of Health Communication, 19, 2 (2014), 89-105.

[9] Soto Mas, F., Ji, M., Fuentes, B. O., Tinajero, J. The Health Literacy and ESL Study: A Community-Based Intervention for Spanish-Speaking Adults. Journal of Health Communication, 20, 4 (2015), 369-376.

[10] Yang, Y. M., Wang, H. H., Lee, F. H., Lin, M. L., Lin, P. C. Health empowerment among immigrant women in transnational marriages in Taiwan. Journal of Nursing Scholarship, 47, 2 (2015), 135-42.

[11] Kiropoulos, L. A., Griffiths, K. M., Blashki, G. Effects of a Multilingual Information Website Intervention on the Levels of Depression Literacy and Depression-Related Stigma in Greek-Born and Italian-Born Immigrants Living in Australia: A Randomized Controlled Trial. Journal of Medical Internet Research, 13, 2 (2011), e34.

[12] Salman, R. Mit Migranten für Migranten- Interkulturelle Gesundheit in Deutschland (MiMi) [With Migrants for Migrants- Intercultural Health in Germany (MiMi)], 2006.

[13] Reiter, A. Evaluierung "Gesundheit kommt nachhause - Mehr Wissen hilft!" [Evaluation "Health is coming home - more knowledge helps!'], 2012.

[14] Riggs, E., Yelland, J., Duell-Piening, P., Brown, S. J. Improving health literacy in refugee populations. Medecial Journal of Australia, 204, 1 (2016), 9-10.

[15] European Commission. Project Summary Migrant-Friendly Hospitals Project, 2005.

[16] Kim, K., Han, H. Potential links between health literacy and cervical cancer screening behaviors: a systematic review. Psycho-Oncology, 25, 2 (2016) 122-130.

[17] McAlister, C., Baskett, T. F. Female Education and Maternal Mortality: A Worldwide Survey. Journal of Obstetrics and Gynaecology Canada, 28, 11 (2006), 983-990.

[18] Van den Muijsenbergh, M., Vermeer, B. Geringe deelname migrantenvrouwen aan borstkankerscreening [Low participation of migrant women for breast cancer screening]. Epidemiologisch Bulletin, 46, 1 (2011), 12-15.

[19] Visser, O., van Peppen, A. M., Ory, F. G., van Leeuwen, F. E. Results of breast cancer screening in first generation migrants in Northwest Netherlands. European Journal of Cancer Prevention, 14, 3 (2005), 251-5. 
[20] Kristiansen, M., Thorsted, B. L., Krasnik, A., von EulerChelpin, M. Participation in mammography screening among migrants and non-migrants in Denmark. Acta Oncologica, 51, 1 (2012), 28-36.

[21] Fontana, M., Bischoff, A. Uptake of breast cancer screening measures among immigrant and Swiss women in Switzerland. Swiss Medical Weekly, 138, 49-50 (2008), 752-8.
[22] Berens, E., Stahl, L., Yilmaz-Aslan, Y., Sauzet, O., Spallek, J., Razum, O. Participation in breast cancer screening among women of Turkish origin in Germany - a register-based study. BMC Womens Health, 14, (2014), 24.

[23] Pedersen, G. S., Grøntved, A., Mortensen, L. H., Andersen, A. M., Rich-Edwards, J. Maternal mortality among migrants in Western Europe: a meta-analysis. Maternal Child Health Journal, 18, 7 (2014), 1628-38. 